\title{
Abscisic Acid, One of the Key Determinants of in Vitro Shoot Differentiation from Cotyledons of Vigna radiata
}

\author{
Suparna Ghosh, Saswati Sengupta, Amita Pal ${ }^{*}$ \\ Division of Plant Biology, Bose Institute, Kolkata, India \\ Email: ${ }^{*}$ amita@jcbose.ac.in
}

Received 13 December 2013; revised 16 February 2014; accepted 6 March 2014

Copyright (C) 2014 by authors and Scientific Research Publishing Inc.

This work is licensed under the Creative Commons Attribution International License (CC BY). http://creativecommons.org/licenses/by/4.0/

(c) (i) Open Access

\section{Abstract}

Differential regeneration potentiality of two cotyledons (Cot and Cot E) of Vigna radiata seed during in vitro shoot differentiation is now well established. In the present study, endogenous abscisic acid (ABA) level (both bound and free form) was estimated using high performance liquid chromatography technique from these two explant types prior to the induction of in vitro differentiation. Both free and conjugated forms of endogenous ABA were higher in Cot than Cot E. However, the bound form of ABA was higher than free or active form in both the explants. Effects of an ABA catabolic inhibitor, diniconazole on the endogenous $A B A$ production potential were determined. Diniconazole inhibits ABA 8'-hydroxylase, the catabolizing enzyme, resulting in accumulation of free $A B A$ in the cell. It was noted that diniconazole inhibited bound form of ABA formation in a concentration dependant manner with a concomitant increase in the free form and decrease in shoot differentiation from Cot $\mathrm{E}$ explants. Likewise, exogenously applied $\mathrm{ABA}$ in in vitro culture also resulted in decrease in shoot regeneration frequency from the cotyledonary explants ascertaining the differential level of endogenous $A B A$ is one of the determinants of differential regeneration response of Cot and Cot $E$ under in vitro cultural condition. Cytokinin antagonized inhibitory effect of ABA mediated by cytokinin responsive proteins, such proteins are up regulated differentially in Cot $\mathrm{E}$ has recently shown us through proteomic study confirming further the role of ABA.

\section{Keywords}

Abscisic Acid; Cotyledons; Diniconazole; Vigna radiata

\footnotetext{
*Corresponding author.
}

How to cite this paper: Ghosh, S., et al. (2014) Abscisic Acid, One of the Key Determinants of in Vitro Shoot Differentiation from Cotyledons of Vigna radiata. American Journal of Plant Sciences, 5, 704-713. 


\section{Introduction}

Plant growth regulators (PGRs) are the critical media components that irrefutably govern in vitro organogenesis. The types, combinations and concentrations of PGRs in basal nutrient medium characteristically regulate different kinds of morphogenic responses under in vitro conditions [1]. Levels of endogenous PGRs also play critical role in creating variations in morphogenetic potentials as has been manifested in different cereal genotypes [2]. Optimal levels of requisite PGRs have to be present within competent cells of the explants to stimulate induction of organ differentiation, which often makes exogenous application of PGRs more decisive. Exogenously applied PGRs induce organ differentiation either directly or intercede by changing endogenous PGR levels. Variations in the sensitivity of various explants, originating from diverse plant species, to the externally applied PGRs in the nutrient medium are basically due to the difference in their endogenous PGR levels. Accordingly, developmental phenomena are governed not only by the rate of uptake of the exogenously supplied PGRs in the explants, but also through the biosynthesis, metabolism and degradation of the endogenous PGRs that eventually produce the active form of the growth regulator(s) to stimulate signal transduction events [3]. In a nut shell, it can be stated that endogenous PGR level discreetly regulates the uptake and metabolism of the external PGRs leading to differential regeneration response in various explants.

Abscisic acid (ABA) is known as a plant growth suppressive PGR. The inhibitory effect of ABA on growth can be attributed to limited cell extensibility and inhibition of cell division cycle [4]. ABA exerts its effect on cell division by inducing expression of cell cycle inhibitors and thereby arrests cell divisions [5]. It also renders its growth retardation function either by inhibiting DNA synthesis [6], protein synthesis [7] or by blocking cell cycle progression at the initial stages [8]. Besides ABA's role in counteracting the growth promoting function of cytokinin, growth alteration in shoot apical meristem was also noted in ABA supersensitive mutants of Arabidopsis thaliana [9]. Christianson [10] has demonstrated that ABA prevented the formation of shoot buds even under cytokinin stimulation in Funaria hygrometrica. Similar association of higher amount of endogenous ABA with inhibition of shoot growth was reported by Saab et al. [11].

The level of biologically active, free form of ABA within a cell is regulated by the rate of ABA biosynthesis followed by its catabolism. ABA catabolism can occur by following either of the two processes: oxidation to phaseic acid or conjugation with glucose to form glucose-ester [12]. However, ABA catabolism through oxidative pathway is predominant in imbibed Arabidopsis seeds [13]. Therefore, in order to validate biological role of ABA with reference to in vitro differentiation, utilization of an inhibitor that regulates rate-limiting steps of ABA catabolism, such as diniconazole, to enhance the active (free form) ABA level, seems highly sensible approach to gain from during the present course of investigation.

Differential in vitro regeneration response was noted between two cotyledon types (Cot and Cot E) of a mature mungbean seed with respect to both mode of shoot differentiation and shoot regeneration efficiency when grown separately in shoot induction medium (SIM) [14]. Such divergence in regeneration response was further confirmed in subsequent studies [15] [16]. Observably, the ceiling level of endogenous ABA has been recorded during seed maturation and at the onset of primary dormancy [17]. Recently, we have reported that differential regeneration response is the consequence of differential regulation of proteins in Cot and Cot E explants at proteomic level, when grown separately under the same chemical and physical mileau [18]. Under the backdrop of above observation, it was presumed that variations in the endogenous ABA contents of these two cotyledonary explants of mature seeds may differentially participates in inducing shoot regeneration. The present study was designed accordingly to estimate the endogenous ABA contents in these two explants before induction of in vitro differentiation. To analyze endogenous ABA level, high performance liquid chromatography (HPLC) technique was employed. The effects of ABA catabolic inhibitor, i.e. diniconazole and exogenous ABA on in vitro response were studied to establish the anticipated role of ABA in in vitro shoot regeneration in Vigna radiata.

\section{Materials and Methods}

\subsection{Plant Materials}

Seeds of Vigna radiata (L) Cv. B1 were collected from the Berhampore Pulse and Oil Seed Research Station, West Bengal, India, and multiplied at the Madhyangram Experimental Farm of Bose Institute. The seeds were treated with $0.1 \%$ mercuric chloride solution and washed thoroughly 3 - 4 times with sterilized double distilled water. The seeds were then imbibed for $22 \mathrm{hr}$ in sterilized water and kept at $30^{\circ} \mathrm{C}$. The cotyledons were excised after removal of the seed coat. These two cotyledons (Cot and Cot E) were used as separate explants and placed 
in Gamborg's B5 basal nutrient medium [19] supplemented with 2\% sucrose and $15 \mu \mathrm{M}$ benzyladenine (BA). The $\mathrm{pH}$ of the medium was adjusted to 5.8 prior to autoclaving and was solidified with $0.8 \%$ agar. Cultures were maintained under photoperiodic condition (16/8 h day night cycles) of cool-white fluorescent light providing a quantum flux density of $27 \mu \mathrm{mol} \cdot \mathrm{m}^{-2} \cdot \mathrm{s}^{-1}$ and were incubated at $25^{\circ} \mathrm{C} \pm 1^{\circ} \mathrm{C}$.

Experiments were conducted taking proximal parts of the excised cotyledonary explants (Cot and Cot E). Abscisic acid was purchased from Sigma and used as control. Diniconazole was purchased from Fluka.

\subsection{Sample Preparation for ABA Analysis}

Analysis of ABA was done following method of Robinson and Barrit [20], modified by Su et al. [21]. Briefly, fresh tissues $(1 \mathrm{~g})$ were grounded with a homogenizer and then extracted 3 times with $10 \mathrm{ml}$ of $80 \%(\mathrm{v} / \mathrm{v})$ methanol: water:acetic acid $=80: 20: 1(\mathrm{v} / \mathrm{v})$. The residue was re-extracted in the same solvent overnight at $4^{\circ} \mathrm{C}$ in the dark. The extracts were filtered through Millipore filter paper $(0.2 \mu)$, and solvent was evaporated in vacuo at $35^{\circ} \mathrm{C}$ to the aqueous phase. A buffer solution $\left(0.2 \mathrm{~mol}^{-1} \mathrm{KH}_{2} \mathrm{PO}_{4}, \mathrm{pH} 8.0\right)$ was added to the aqueous phase and the $\mathrm{pH} 8.0$ was adjusted with $2 \mathrm{~N} \mathrm{NaOH}$.

Extract was purified twice with n-hexane. The aqueous phase was adjusted to $\mathrm{pH} 3.0$ with $2 \mathrm{~N} \mathrm{HCl}$, and extracted with ethyl acetate ( $3 \times 1 / 2$ volume). The remaining aqueous phase was retained to estimate bound ABA. The ethyl acetate phase was evaporated to dryness in vacuo at $35^{\circ} \mathrm{C}$, then dissolved in methanol prior to addition of polyvinylpyrrolidone (PVP). The mixture was then filtered with Millipore filter paper and dried in vacuo at $35^{\circ} \mathrm{C}$. Finally the residue was dissolved in methanol, diluted with $0.01 \mathrm{~mol}^{-1} \mathrm{KH}_{2} \mathrm{PO}_{4}$ and the $\mathrm{pH}$ was adjusted at 2.8. The extract was purified 3 times with ethyl acetate and the organic phase was evaporated to dryness under vacuum at $35^{\circ} \mathrm{C}$. Dried residues were redissolved in methanol and used for HPLC analysis.

The aqueous phase containing bound $\mathrm{ABA}$ was adjusted at $\mathrm{pH} 10.5$ with $2 \mathrm{~N} \mathrm{NaOH}$ and heated to $60^{\circ} \mathrm{C}$ for $1 \mathrm{hr}$. The $\mathrm{pH}$ was then adjusted at 2.8 with $2 \mathrm{~N} \mathrm{HCl}$ and extracted with ethyl acetate $(3 \times 1 / 2 \mathrm{vol})$. Combined ethyl acetate extracts were evaporated to dryness under vacuum at $35^{\circ} \mathrm{C}$, dissolved in methanol and used for HPLC analysis.

\subsection{Endogenous ABA Extraction and Analysis in Presence of Diniconazole}

Seeds were imbibed in presence of four different concentrations of diniconazole, 10, 20, 40 and $80 \mu \mathrm{M}$. De-embryonated cotyledons (Cot and Cot E) were then excised after $22 \mathrm{hr}$ imbibitions. One set of these explants was then used for endogenous ABA analysis, another set of explants was cultured in vitro. All sets of experiments were repeated three times and results are represented as mean \pm standard error. Statistical difference between mean tabulated values was estimated $(\mathrm{P} \leq 0.05)$ using Duncan's multiple range test (DMRT) by SPSS version 17.0.

\subsection{Quantitative Assay of ABA Employing HPLC}

High performance liquid chromatography (HPLC) was performed using C18 column ( $\mu$ Bondapak $30 \times 0.4 \mathrm{~cm}$ ) of the HPLC equipment (Waters Associates). Solvent system comprised of $1 \%$ acetic acid in water (A) and methanol in $1 \%$ acetic acid (B). Elution was programmed for a total run time of $30 \mathrm{~min}$ at a flow rate of $1 \mathrm{ml} \cdot \mathrm{min}^{-1}$. There was a 15 min linear gradient of 20-80-20\% B solvent. The peak in the chromatogram corresponding to the retention time (RT) and UV absorbance maxima ( $\lambda \max )$ of authentic ABA was matched with that of ABA present in samples. Quantification of ABA in samples was calibrated from the standard curve generated using six different concentrations of authentic ABA.

\subsection{Exogenous ABA Supplementation in the Shoot Regenerating Medium}

Stock solution of ABA was prepared by dissolving in methanol. The solution was filter sterilized followed by dilution in sterile water and added to the autoclaved SIM in a Petri dish at final concentrations of 20, 40, 60, 80 and $100 \mathrm{nM}$ and the explants (Cot and Cot E) were cultured. Modes of differentiation and regeneration frequencies were recorded on $6^{\text {th }}, 9^{\text {th }}$ and $12^{\text {th }}$ days.

\subsection{Growth of Diniconazole Treated Explants in Shoot Regenerating Medium}

The explants were excised from four different concentrations of diniconazole $(10,20,40,80 \mu \mathrm{M})$ treated seeds 
and were cultured in $15 \mu \mathrm{M}$ BA containing Gamborg's B5 nutrient medium [19]. Two control sets with Cot and Cot $\mathrm{E}$ explants were cultured in the same medium without diniconazole treatment. Regeneration frequencies were recorded on the $6^{\text {th }}$ and $9^{\text {th }}$ day post inoculation.

\section{Results}

\subsection{Endogenous ABA Contents of Cot and Cot E Explants}

ABA was detected with a fixed wavelength of UV detector at $254 \mathrm{~nm}$ (Figure 1) and the peak containing ABA was eluted at RT of 11 min. Standard ABA was eluted from the HPLC column as a single dominant peak. The corresponding peak of ABA present in the sample denotes a relatively purified sample preparation without presence of any major interfering substance. Conjugated or bound ABA was measured by alkaline hydrolysis of the residual aqueous phase after partitioning the acidic fraction into ethyl acetate solvent. ABA present in the sample was calibrated from the standard curve prepared using known ABA concentrations. Results indicated that amount of both free and conjugated forms of endogenous ABA was higher in Cot than in Cot E (Figure 2). Quantitative difference in both free and bound forms of ABA between the two explants was statistically significant at $\mathrm{p} \leq 0.05$. The bound form of ABA was higher than free or active form in both the explants, although the difference was insignificant in Cot.

\subsection{Endogenous ABA Contents of Cotyledonary Explants after Treatment with Diniconazole}

Endogenous ABA contents of two explants were measured following 10, 20, 40 and $80 \mu \mathrm{M}$ diniconazole treatments. Quantitative analysis of ABA in the cotyledonary explants after diniconazole treatment revealed that with the increase in inhibitor concentrations from 10 to $80 \mu \mathrm{M}$, there is a gradual increase in the amount of free form of $\mathrm{ABA}$ and a concomitant decrease in the bound form of ABA, though the level was always higher in Cot than Cot $\mathrm{E}$ in each sample (Figure 3).

\subsection{Effects of ABA Supplementation on Shoot Regeneration Frequency of Cotyledonary Explants}

Shoot regeneration frequencies of Cot $\mathrm{E}$ explants decreased with the increase in exogenous ABA concentrations (Table 1). The regeneration frequency noticeably declined from control set for both the Cot and Cot E explants

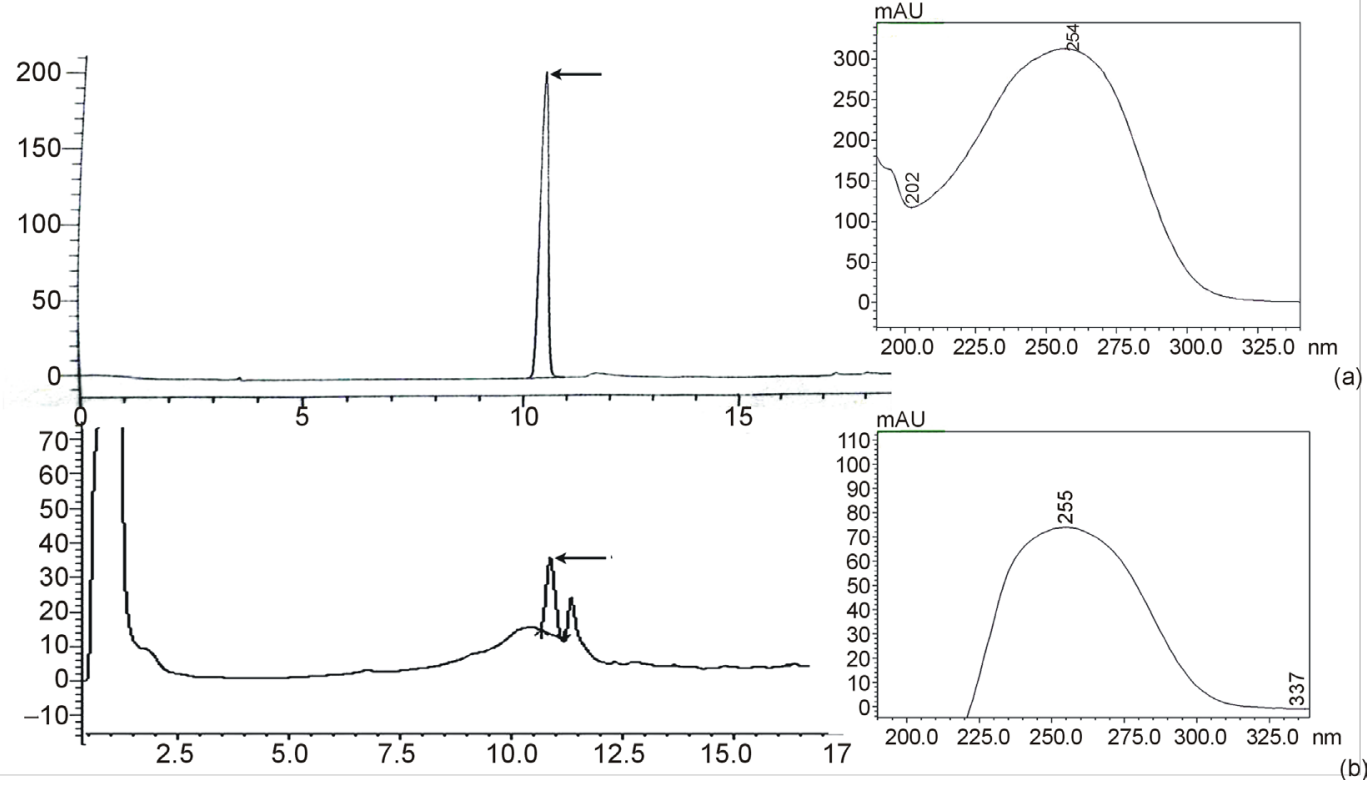

Figure 1. Retention time (RT) and UV absorbance maxima ( $\lambda \max$ ) of (a) standard ABA and (b) ABA present in the sample. ABA peaks are marked with arrows. 


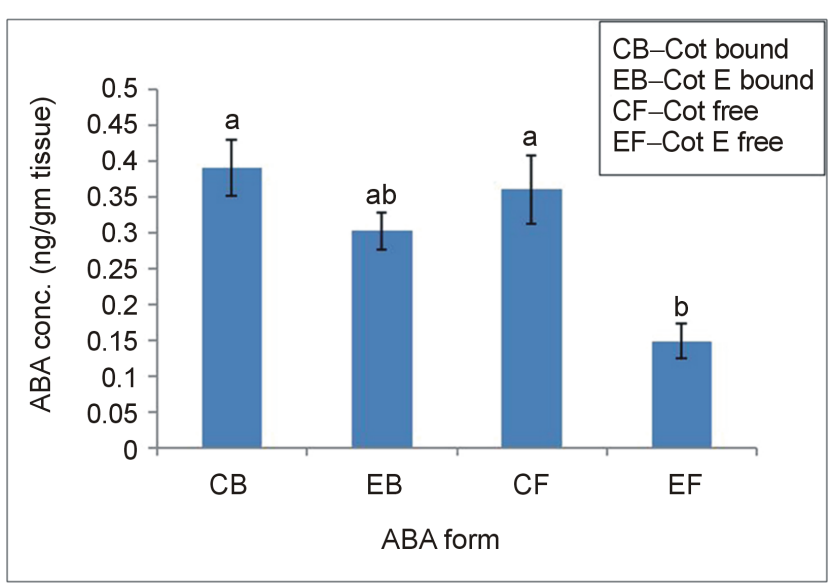

Figure 2. Bound and free ABA contents in Cot and Cot E explants on 0 day (after $22 \mathrm{~h}$ imbibitions). Different letters upon the bars represent significant differences among the means when one-way ANOVA was performed at a pre-set alpha of $5 \%$.

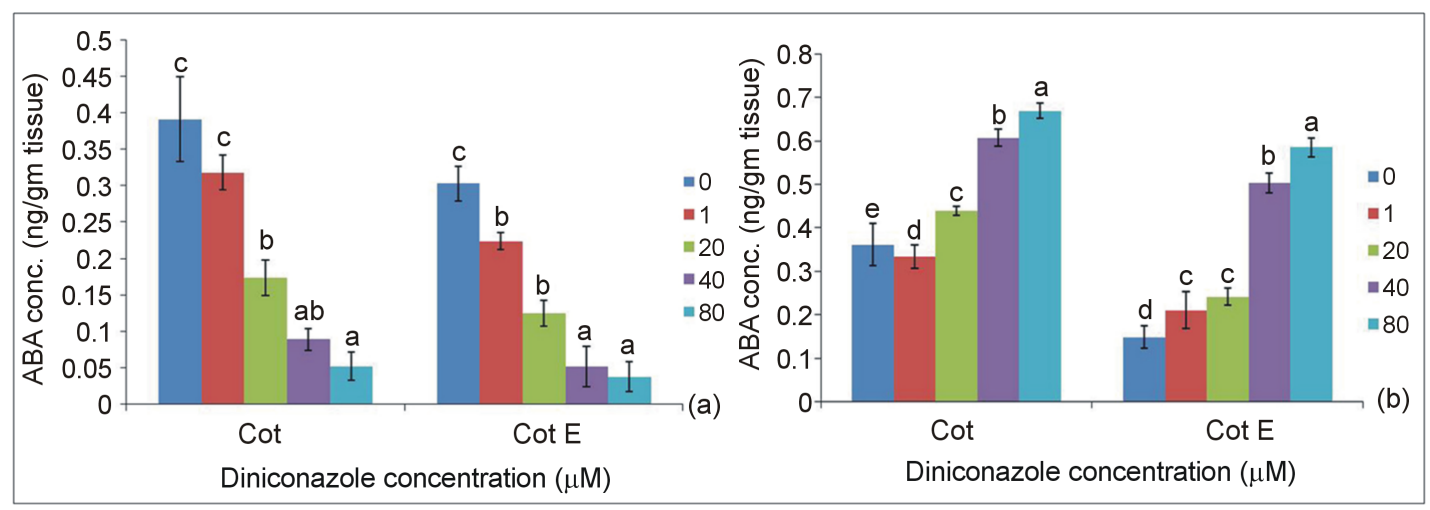

Figure 3. (a) Bound and (b) Free ABA contents in Cot and Cot E explants at 0d in presence of 10, 20, 40 and 80 $\mu \mathrm{M}$ diniconazole in the SIM. Different letters $(\mathrm{a}, \mathrm{b}$ and $\mathrm{c})$ within each group designate significantly different means as determined by Duncan's multiple range test $(\mathrm{P}<0.05)$.

Table 1. Shoot regeneration frequency of Cot and Cot E explants in the shoot induction medium supplemented with different concentrations of ABA.

\begin{tabular}{|c|c|c|c|c|}
\hline \multirow{2}{*}{ Explant type } & \multirow{2}{*}{ Concentrations of ABA (nM) } & \multicolumn{3}{|c|}{ Shoot regeneration frequency ${ }^{*}$} \\
\hline & & 6 Day & 9 Day & 12 Day \\
\hline \multirow{6}{*}{ Cot $\mathbf{E}$} & 0 & $86.28 \pm 3.40^{c}$ & $88.56 \pm 3.60^{\mathrm{e}}$ & $95.80 \pm 3.65^{f}$ \\
\hline & 20 & $70.59 \pm 2.80^{\mathrm{bc}}$ & $75.98 \pm 0.85^{\mathrm{d}}$ & $80.33 \pm 0.58^{\mathrm{e}}$ \\
\hline & 40 & $53.71 \pm 3.21^{\mathrm{b}}$ & $68.75 \pm 4.25^{\mathrm{c}}$ & $72.50 \pm 3.44^{\mathrm{d}}$ \\
\hline & 60 & $29.63 \pm 2.62^{\mathrm{ab}}$ & $41.67 \pm 3.60^{\mathrm{b}}$ & $57.14 \pm 3.69^{\mathrm{cd}}$ \\
\hline & 80 & $12.96 \pm 3.11^{\mathrm{a}}$ & $27.29 \pm 2.96^{\mathrm{ab}}$ & $51.11 \pm 4.14^{\mathrm{cd}}$ \\
\hline & 100 & $7.84 \pm 2.28^{\mathrm{a}}$ & $17.65 \pm 3.15^{\mathrm{a}}$ & $33.33 \pm 3.60^{\mathrm{b}}$ \\
\hline \multirow{6}{*}{ Cot } & 0 & \multirow{6}{*}{ Callus formation } & $61.55 \pm 2.97^{c}$ & $70.17 \pm 3.04^{\mathrm{d}}$ \\
\hline & 20 & & $52.95 \pm 4.86^{\mathrm{bc}}$ & $62.50 \pm 2.25^{c}$ \\
\hline & 40 & & $45.13 \pm 3.42^{\mathrm{b}}$ & $43.01 \pm 3.38^{\mathrm{bc}}$ \\
\hline & 60 & & $31.37 \pm 3.98^{\mathrm{ab}}$ & $33.33 \pm 2.90^{\mathrm{b}}$ \\
\hline & 80 & & $25.49 \pm 3.39^{\mathrm{ab}}$ & $23.90 \pm 3.26^{\mathrm{ab}}$ \\
\hline & 100 & & $13.75 \pm 3.45^{\mathrm{a}}$ & $15.68 \pm 3.79^{\mathrm{a}}$ \\
\hline
\end{tabular}

\footnotetext{
*Values are represented as Mean \pm SD; data followed by different alphabets in a column are significantly different at $\mathrm{p} \leq 0.05$ according to DMRT.
} 
on $9^{\text {th }}$ day especially at relatively higher concentrations of ABA (80 and $100 \mathrm{nM}$ ). Majority of the Cot E explants, like those of Cot explants, produced callus instead of shoot induction in presence of exogenous ABA (Figures 4(a) and (b)). Moreover the regeneration frequency of the Cot E explants still increased with the progression of culture period in advanced days while in case of Cot explants it was roughly similar in most instances.

\subsection{Effect of Diniconazole Treatment on Shoot Regeneration Frequency}

Shoot regeneration frequency was found to decrease with diniconazole treated Cot E explants upon culturing on SIM. The Cot explants showed callus formation like that of the control explants (Figure 4(b)). Nevertheless, majority of Cot E explants showed initiation of shoot regeneration (Table 2). Shoot regeneration frequency gradually decreased at significant level in Cot E explants with concomitant increase in the diniconazole concentrations. Decrease in shoot regeneration potentiality of Cot E explants treated with 40 and $80 \mu \mathrm{M}$ diniconazole was comparable to that of the ABA treated explants. Callus formation was noted from Cot E explants (Figure 4(a)) and shoot regeneration was significantly low with $80 \mu \mathrm{M}$ diniconazole concentration even in presence of SIM after 9 days of culture (Table 2).

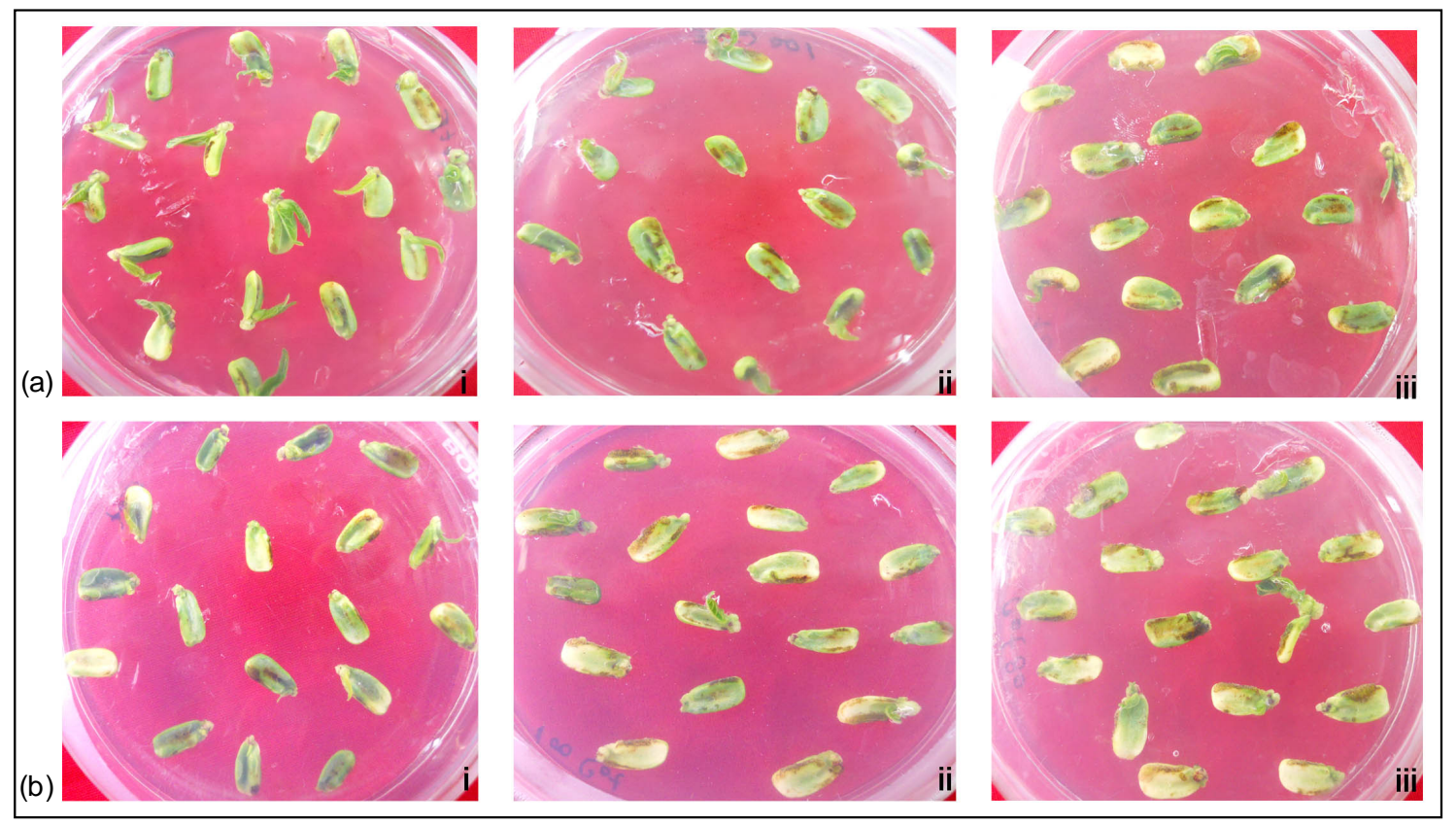

Figure 4. Effects of external ABA and diniconazole on in vitro shoot regeneration. Panel (a) Cot E explants in (i) SIM (Control); in (ii) SIM + $100 \mathrm{nM} \mathrm{ABA}$; in (iii) SIM $+80 \mu \mathrm{M}$ diniconazole. Panel (b) Cot explants in (i) SIM (Control); in (ii) SIM + $100 \mathrm{nM} \mathrm{ABA}$; in (iii) SIM $+80 \mu \mathrm{M}$ diniconazole at 9 days.

Table 2. Shoot regeneration frequency of Cot E explants in the shoot induction medium supplemented with different concentrations of diniconazole.

\begin{tabular}{ccc}
\hline \multirow{2}{*}{$\begin{array}{c}\text { Diniconazole } \\
\text { (in } \boldsymbol{\mu M})\end{array}$} & \multicolumn{2}{c|}{ Shoot regeneration frequency $^{*}$} \\
\cline { 2 - 3 } & $\mathbf{6}$ Day & 9 Day \\
10 & $73.68 \pm 2.74^{\mathrm{e}}$ & $84.21 \pm 2.84^{\mathrm{e}}$ \\
20 & $68.42 \pm 3.02^{\mathrm{d}}$ & $74.95 \pm 2.37^{\mathrm{d}}$ \\
40 & $52.63 \pm 2.01^{\mathrm{c}}$ & $65.33 \pm 3.29^{\mathrm{c}}$ \\
80 & $21.69 \pm 3.64^{\mathrm{b}}$ & $26.74 \pm 2.92^{\mathrm{b}}$ \\
\hline
\end{tabular}

\footnotetext{
*Values are represented as Mean \pm SD; data followed by different alphabets in a column are significantly different at $\mathrm{p} \leq 0.05$ according to DMRT.
} 


\section{Discussion}

ABA is well known for its role in the induction and maintenance of seed dormancy. Highest endogenous level of ABA has been recorded during seed maturation and at the onset of dormancy [17]. The biological activity of ABA is controlled either by conjugation with glucose to form ABA glucosyl ester (ABA-GE), or through oxidation to phaseic acid (PA), dihydrophaseic acid (DPA), DPA-glucosides (DPA-GS) [22]. These oxidized forms render ABA inactive and regulate the endogenous concentration of ABA [12]. ABA level decreased upon release of seed dormancy during seed imbibition leading to germination, as found in several plant species [23], [24]. Kushiro and co-workers [13] found that ABA catabolism was active during imbibition period in Arabidposis and the level of catabolites, viz. PA and DPA, was increased. Hence, the free active form of ABA decreased and bound form increased in the imbibed seeds.

\subsection{Endogenous ABA Contents in V. radiata Cotyledonary Explants}

In $V$. radiata, bound form of ABA was higher than the free form in both the cotyledonary explants after imbibition, which is in agreement with the findings of Kushiro et al. [13]. ABA plays important developmental role in response to various environmental stresses through regulated expression of many stress responsive genes [17]. Hence, even in presence of active form of ABA at lower level in the cotyledonary explants, it encounters the cultural stresses to a limited extent allowing in vitro differentiation.

Wang and others [5] have demonstrated that one cyclin-dependent kinase (CDK)-inhibitor gene expression was induced by ABA in A. thaliana. CDKs are cyclin dependent regulators of plant cell cycle and it was presumed that ABA inhibits cell division. Swiatek et al. [8] have demonstrated that ABA can arrest cell cycle progression at the initial phase of cell division. Amaral Da Silva and his associates [25] have shown that ABA inhibits the abundance of microtubule, microtubule-reorganization and DNA replication in germinating coffee seeds. Therefore the negative effects of ABA on seed germination can be attributed to inhibition of DNA synthesis, spindle formation, chromatid separation, decreased transcription rate, rRNA gene hypoacetylation [26] and inhibition of protein synthesis [7]. Interestingly, ABA deficient mutants of Arabidopsis showed an early germinating phenotype [27] [28]. In contrast, ABA is known to play a positive role in seed maturation and dormancy [27] [29]. In the present study, comparatively higher amounts of both free (the biologically active form) and conjugated forms of endogenous ABA was found in the Cot than that in the Cot E explants of mature V. radiata seeds, indicating the possible role of higher ABA content in the former explant type in delaying the shoot regeneration response.

Cytokinin is known to alter the negative effect of ABA on cell cycle arrest as an antagonist. Such antagonistic crosstalk occurs via signal transduction pathways. Khan [30] has shown that cytokinins reversed inhibition of lettuce seed germination caused by several naturally occurring inhibitors including ABA. ABA inhibits transcripts of the cytokinin biosynthesis gene, isopentenyl transferase [31]. Recently we have shown through proteomic study that there was up regulation of several cytokinin responsive proteins including cytokinin signaling proteins, extracellular invertase, PR10, isopentenyltransferase in Cot E during in vitro morphogenesis in presence of exogenously supplied cytokinin, which perhaps regress the ABA mediated inhibition of shoot regeneration [18]. Active form of ABA was present in significantly lower amount in Cot E than Cot explants, which perhaps helps in maintaining cellular cytokinin homeostasis in the former explant. Nishiyama and co-researchers [31] have shown evidences for such mutual regulation between the ABA and cytokinin in metabolism, and in signaling control underlying different biological processes including plant growth/development and adaptation to stress. The antagonistic function of cytokinin and ABA in plant tissue culture has also been supported by Kano and Asahira [32] and Christianson [10].

\subsection{ABA Catabolism and Mode of Action of Diniconazole}

The level of ABA in any particular tissue of a plant is determined by the rate of its biosynthesis and catabolism. However catabolism of ABA is predominant in germinating seeds [33]. There are several metabolic pathways of ABA catabolism [22], of which oxidative pathway is the major one leading to the formation of PA that is triggered by hydroxylation at C-8' by the enzyme - ABA 8'-hydroxylase to produce 8'-hydroxy ABA [13]. Diniconazole is an inhibitor of the ABA-catabolizing enzyme, i.e. ABA 8'-hydroxylase, resulting in accumulation of free $\mathrm{ABA}$ in the cell. It is evident from the present study that diniconazole inhibits the formation of bound form 
of $\mathrm{ABA}$ in a concentration dependant manner and subsequently the amount of free $\mathrm{ABA}$ increased in the cotyledonary tissues.

\subsection{Exogenously Applied ABA and Diniconazole on in Vitro Shoot Regeneration}

The present finding demonstrated that ABA supplementation in the nutrient medium has a negative effect on in vitro shoot regeneration. ABA delays the shoot initiation and the regeneration frequency declines in Cot E explants (Table 1). In presence of external ABA at higher concentration, mode of differentiation of Cot E explants alters like that of Cot explants. Similarly, application of diniconazole also exhibited the inhibitory effect on shoot differentiation in V. radiata from Cot E explants especially at 40 and $80 \mu \mathrm{M}$ concentrations. On the contrary, Yoshioka et al. [34] used fluridone, an inhibitor of ABA biosynthesis to restore seed germination.

Braun and Khan [35] have shown variations in the endogenous ABA levels in germinating and non-germinating lettuce seeds. The present results are in concurrence with the previous reports, i.e. shoot regeneration efficiency of Cot E declined with the increasing concentration of diniconazole, which concomitantly increases the endogenous free ABA concentration.

Regeneration response of explants in SIM supplemented with exogenous ABA was similar to that of diniconazole treated explants. Significant decline in shoot regeneration frequency with $80 \mu \mathrm{M}$ diniconazole treatment indicates that regeneration response can be decelerated in presence of comparatively high concentration of free form of ABA. This situation is analogous to that of the Cot explants where relatively higher amount of endogenous $\mathrm{ABA}$ regulates this explant to respond sluggishly even under appropriate shoot induction milieu. Therefore, it can be inferred that active form of ABA interferes with cytokinin mediated morphogenic induction in $V$. radiata as has been shown earlier in Funaria hygrometrica [10]. It may be concluded that tissues of $V$. radiata containing up to $0.15 \mathrm{ng}^{\text {-gm }}$ tissue of free $\mathrm{ABA}$ are amenable to shoot differentiation in presence of an appropriate concentration of cytokinin. Cytokinin, as an antagonist, alleviates the negative effect of ABA on growth. It was further supported by our recent proteomic study, which revealed that Cot explants are deficient in terms of protein synthesis, and down regulation of cytokinin signaling protein (histidine phosphotransfer protein) as well as cytokinin biosynthesis protein (isopentenyltransferase, extracellular invertase) occurred during in vitro culture in presence of exogenously applied cytokinin [18]. Due to the inefficient endogenous cytokinin biosynthesis machinery in this explant tissue, unlike Cot E, the induction of shoot differentiation got delayed, which normally occurs through perceiving the acquired PGR signals by the competent cells. Conversely, the adverse effect of $\mathrm{ABA}$ is deactivated by higher internal cytokinin pool in the Cot E explant.

\section{Conclusion}

From the present study, it is indicative that ABA is one of the key determinants that decide the mode of in vitro differentiation of cotyledonary explant types; and the direct shoot regeneration is delayed in Cot due to the presence of higher amount of ABA in the active form. Presence of higher amount of ABA in Cot explants also indicates less endogenous cytokinin responsive proteins, which have previously been demonstrated by us through proteomic investigation [18]. On the other hand, up regulation of several cytokinin responsive proteins in Cot $\mathrm{E}$ during induction of in vitro shoot differentiation in presence of exogenously applied cytokinin in nutrient medium reduces the ABA activity maintaining cellular cytokinin homeostasis. Hence, this investigation clearly demonstrates the role of ABA as determinants of shoot differentiation in Vigna radiata.

\section{Acknowledgements}

Authors are thankful to the Department of Science and Technology, Government of India (DST Sanction No. SR/SO/PS-58/05) for financial support and to the Director, Bose Institute for providing all infrastructural facilities.

\section{References}

[1] Skoog, F. and Miller, C.O. (1957) Chemical Regulation of Growth and Organ Formation In Plant Tissue Cultured in Vitro. Symposia of the Society for Experimental Biology, 11, 118-131.

[2] Bhaskaran, S. and Smith, R.H. (1990) Regeneration in Cereal Tissue Culture: A Review. Crop Science, 30, $1328-1336$. http://dx.doi.org/10.2135/cropsci1990.0011183X003000060034x 
[3] Auer, C.A., Motyka, V., Brezinova, A. and Kamınek, M. (1999) Endogenous Cytokinin Accumulation and Cytokinin Oxidase Activity during Shoot Organogenesis of Petunia Hybrid. Physiologia Plantarum, 105, 141-147. http://dx.doi.org/10.1034/j.1399-3054.1999.105121.x

[4] Finkelstein, R.R., Gampala, S.S.L. and Rock, C.D. (2002) Abscisic Acid Signaling in Seeds and Seedlings. Plant Cell, 14, S15-S45.

[5] Wang, H., Qi, Q., Schorr, P., Cutler, A.J., Crosby, W.L. and Fowke, L.C. (1998) ICK1, a Cyclin-Dependent Protein Kinase Inhibitor from Arabidopsis thaliana Interacts with both Cdc2a and CycD3, and Its Expression Is Induced by Abscisic Acid. Plant Journal, 15, 501-510. http://dx.doi.org/10.1046/j.1365-313X.1998.00231.x

[6] Stewart, G.R. and Smith, H. (1972) Effects of Abscisic Acid on Nucleic Acid Synthesis and the Induction of Nitrate Reductase in Lemna polyrhiza. Journal of Experimental Botany, 23, 875-885. http://dx.doi.org/10.1093/jxb/23.4.875

[7] Mullins, M.G. and Osborne, D.J. (1970) Effect of Abscisic Acid on Growth Correlation in Vitis vinifera L. Australian Journal of Biological Sciences, 23, 479-83.

[8] Światek, A., Lenjou, M., Bockstaele, D.V., Inzé, D. and Onckelen, H.V. (2002) Differential Effect of Jasmonic Acid and Abscisic Acid on Cell Cycle Progression in Tobacco BY-2 cells. Plant Physiology, 128, 201-211. http://dx.doi.org/10.1104/pp.010592

[9] Bonetta, D., Bayliss, P., Sun, S., Sage, T. and McCourt, P. (2000) Farnesylation Is Involved in Meristem Organization in Arabidopsis. Planta, 211, 182-190. http://dx.doi.org/10.1007/s004250000283

[10] Christianson, M.L. (2000) ABA Prevents the Second Cytokinin-Mediated Event during the Induction of Shoot Buds in the Moss Funaria hygrometrica. American Journal of Botany, 87, 1540-1545. http://dx.doi.org/10.2307/2656880

[11] Saab, I.N., Sharp, R.E., Pritchard, J. and Voetberg, G.S. (1990) Increased Endogenous Abscisic Acid Maintains Primary Root Growth and Inhibits Shoot Growth of Maize Seedlings at Low Water Potentials. Plant Physiology, 93, 1329-1336. http://dx.doi.org/10.1104/pp.93.4.1329

[12] Cutler, A.J. and Krochko, J.E. (1999) Formation and Breakdown of ABA. Trends in Plant Science, 4, 472-478. http://dx.doi.org/10.1016/S1360-1385(99)01497-1

[13] Kushiro, T., Okamoto, M., Nakabayashi, K., Yamagishi, K., Kitamura, S., Asami, T., Hirai, N., Koshiba, T., Kamiya, Y. and Nambara, E. (2004) The Arabidopsis Cytochrome P450 CYP707A Encodes ABA 80-Hydroxylases: Key Enzymes in ABA Catabolism. EMBO Journal, 23, 1647-1656. http://dx.doi.org/10.1038/sj.emboj.7600121

[14] Chandra, M. and Pal, A. (1995) Differential Response of the Two Cotyledons of Vigna radiata in Vitro. Plant Cell Reports, 15, 248-253.

[15] Das, S. and Pal, A. (2004) Differential Regeneration Response in Two Cotyledons of Vigna radiata: Histomorphological Analysis and Effect of $\beta$-Arabinogalactan. Journal of Plant Biochemistry and Biotechnology, 13, 101-106. http://dx.doi.org/10.1007/BF03263202

[16] Das, S., Sengupta, D.N. and Pal, A. (2006) Differential Protein Pattern of Two Cotyledons of Vigna radiata during Induced in Vitro Differentiation: Probable Implication in the Conundrum of Differential Regeneration Response. Journal of Plant Biochemistry and Biotechnology, 15, 123-129. http://dx.doi.org/10.1007/BF03321915

[17] Seo, M. and Koshiba, T. (2002) Complex Regulation of ABA Biosynthesis in Plants. Trends in Plant Science, 7, 41-48. http://dx.doi.org/10.1016/S1360-1385(01)02187-2

[18] Ghosh, S. and Pal, A. (2013) Proteomic Analysis of Cotyledonary Explants during Shoot Organogenesis in Vigna radiata. Plant Cell, Tissue and Organ Culture, 115, 55-68. http://dx.doi.org/10.1007/s11240-013-0340-0

[19] Gamborg, O.L., Miller, R.A. and Ojima, K. (1968) Nutrient Requirements of Suspension Cultures of Soybean Root Cells. Experimental Cell Research, 50, 151-158. http://dx.doi.org/10.1016/0014-4827(68)90403-5

[20] Robinson, T.L. and Barritt, B.H. (1990) Endogenous Abscisic Acid Concentrations, Vegetative Growth and Water Relations of Apple Seedlings Following PEG-Induced Water Stress. Journal of the American Society for Horticultural Science, 115, 991-999.

[21] Su, W.R., Huang, K.L., Shen, R.S. and Chen, W.S. (2002) Abscisic Acid Affects Floral Initiation in Polianthes tuberose. Journal of Plant Physiology, 159, 557-559. http://dx.doi.org/10.1078/0176-1617-00732

[22] Srivastava, L.M. (2002) Abscisic Acid. In: Srivastava, L.M., Ed., Plant Growth and Development: Hormones and Environment, Elsevier Science, Atlanta, 217-231. http://dx.doi.org/10.1016/B978-012660570-9/50151-9

[23] Grappin, P., Bouinot D., Sotta, B., Miginiac, E. and Jullien, M. (2000) Control of Seed Dormancy in Nicotiana plumbaginifolia: Post-Imbibition Abscisic Acid Synthesis Imposes Dormancy Maintenance. Planta, 210, 279-285. http://dx.doi.org/10.1007/PL00008135

[24] Jacobsen, J.V., Pearce, D.W., Poole, A.T., Pharis, R.P. and Mander, L.N. (2002) Abscisic acid, Phaseic Acid and Gibberellin Contents Associated with Dormancy and Germination in Barley. Physiologia Plantarum, 115, 428-441. http://dx.doi.org/10.1034/j.1399-3054.2002.1150313.x 
[25] Da Silva, E.A. A., Toorop, P.E., Van Lammeren, A.A.M. and Hilhorst, H.W.M. (2008) ABA Inhibits Embryo Cell Expansion and Early Cell Division Events during Coffee (Coffea arabica "Rubi”) Seed Germination. Annals of Botany, 102, 425-433. http://dx.doi.org/10.1093/aob/mcn112

[26] Zhang, L., Hu, Y., Yan, S., Li, H., He, S., Huang, M. and Li, L. (2012) ABA-Mediated Inhibition of Seed Germination Is Associated with Ribosomal DNA Chromatin Condensation, Decreased Transcription, and Ribosomal RNA Gene Hypoacetylation. Plant Molecular Biology, 79, 285-293. http://dx.doi.org/10.1007/s11103-012-9912-3

[27] Koornneef, M., Jorna, M.L., Brinkhorst-van der Swan, D.L.C. and Karssen, C.M. (1982) The Isolation of Abscisic Acid (ABA) Deficient Mutants by Selection of Induced Revertants in Non Germinating Gibberellin Sensitive Lines of Arabidopsis thaliana (L.) Heynh. Theoretical and Applied Genetics, 61, 385-393.

[28] North, H.M., De Almeida, A., Boutin, J.P., Frey, A., To, A., Botran, L., Sotta, B. and Marion-Poll, A. (2007) The Arabidopsis ABA-Deficient Mutant aba4 Demonstrate That the Major Route for Stress-Induced ABA Accumulation Is via Neoxanthin Isomers. Plant Journal, 50, 810-824. http://dx.doi.org/10.1111/j.1365-313X.2007.03094.X

[29] Karssen, C.M., Brinkhorst-van der Swan, D.L.C., Breekland, A.E. and Koornneef, M. (1983) Induction of Dormancy During Seed Development by Endogenous Abscisic Acid: Studies of Abscisic Acid Deficient Genotypes of Arabidopsis thaliana (L.) Heynh. Planta, 157, 158-165. http://dx.doi.org/10.1007/BF00393650

[30] Khan, A.A. (1967) Antagonism between Cylokinins and Germination Inhibitors. Nature, 216, 166-167. http://dx.doi.org/10.1038/216166a0

[31] Nishiyama, R., Watanabe, Y., Fujita, Y., Le, D.T., Kojima, M., Werner, T., Vankova, R., Yamaguchi-Shinozaki, K., Shinozaki, K., Kakimoto, T., Sakakibara, H., Schmülling, T. and Tran, L.S. (2011) Analysis of Cytokinin Mutants and Regulation of Cytokinin Metabolic Genes Reveals Important Regulatory Roles of Cytokinins in Drought, Salt and Abscisic Acid Responses, and Abscisic Acid Biosynthesis. Plant Cell, 23, 2169-2183. http://dx.doi.org/10.1105/tpc.111.087395

[32] Kano, Y. and Asahira, T. (1981) Roles of Cytokinin and Abscisic Acid in the Maturing of Strawberry Fruits. Journal of the Japanese Society for Horticultural Science, 50, 31-36.

[33] Feurtado, J.A., Ambrose, S.J., Cutler, A.J., Ross, A.R.S., Abrams, S.R. and Kermode, A.R. (2004) Dormancy Termination of Western White Pine (Pinus monticola Dougl. Ex D. Don) Seeds Is Associated with Changes in Abscisic Acid Metabolism. Planta, 218, 630-639. http://dx.doi.org/10.1007/s00425-003-1139-8

[34] Yoshioka, T., Endo, T. and Satoh, S. (1998) Restoration of Seed Germination at Supraoptimal Temperatures by Fluridone, an Inhibitor of Abscisic Acid Biosynthesis. Plant and Cell Physiology, 39, 307-312. http://dx.doi.org/10.1093/oxfordjournals.pcp.a029371

[35] Braun, J.W. and Khan, A.A. (1975) Endogenous Abscisic Acid Levels in Germinating and Non-Germinating Lettuce Seed. Plant Physiology, 56, 731-773. http://dx.doi.org/10.1104/pp.56.6.731 